\title{
Exhibition Space Design Research Based on Service Design Thinking: Viewing the Beijing Rehabilitation Technical Aids for Aging Exhibition Hall as an Exemplar
}

\author{
Yafei Ou¹, Xiaochun Wang ${ }^{1}$, Zhenwei You'1, Chunjing Tao², Jian Liu ${ }^{3}$ \\ ${ }^{1}$ Beijing University of Posts and Telecommunications, Beijing, China \\ ${ }^{2}$ National Research Center for Rehabilitation Technical Aids, Beijing, China \\ ${ }^{3}$ Beijing University of Technology, Beijing, China \\ Email: faye927@163.com
}

How to cite this paper: Ou, Y. F., Wang, X. C., You, Z. W., Tao, C. J., \& Liu, J. (2017). Exhibition Space Design Research Based on Service Design Thinking: Viewing the Beijing Rehabilitation Technical Aids for Aging Exhibition Hall as an Exemplar. Art and Design Review, 5, 152-161. https://doi.org/10.4236/adr.2017.53012

Received: May 16, 2017

Accepted: July 3, 2017

Published: July 6, 2017

Copyright $\odot 2017$ by authors and Scientific Research Publishing Inc. This work is licensed under the Creative Commons Attribution International License (CC BY 4.0).

http://creativecommons.org/licenses/by/4.0/

\begin{abstract}
This paper incorporates the Service Design Thinking into the exhibition space design to refine the generality between service design and the display design, and carry out the design practice by combining the science exhibition technology of the aging assistive technology to refine the influence factor and the design method between the service design and the exhibition effect. It explores how to apply the service design thinking efficiently in the concrete practices of the exhibition space design.
\end{abstract}

\section{Keywords}

Service Design, Aging Assistive Technology, Exhibition Space Design

\section{Introduction}

In the early 21st century, the upsurge in service design became a kind of new research tendency in the field of design. The rich and diverse instructional theory made by interdisciplinary guides the designers blend and improve the service design system on all sorts of different levels Service design, as a field of researching service by the design method, can plan and develop the entity elements and unsubstantial elements to improve the user's experience and create the service value (Karmarkar, 2004). Exhibition space is the place to inherit human civilization and diffuse scientific knowledge and culture and it's improved in the process of development by absorbing the new design idea or method. If the exhibition space is regarded as the visual carrier of the service design and the 
communicative channel of participants, and the service concept is used to guide the exhibition space, thus it can diffuse the exhibited content for the public, improve the exhibition service system and create the service value which is beneficial for users.

\section{The Concept of Exhibition Based on Service Design}

\subsection{User-Centered Design}

Service design is a process, which views from the request of customers, using the creative thinking, "Human Oriented" tenet and ways of user involvement to determine the service pattern and content (Li, Ming, \& Kong, 2008). The service design thinking emphasizes the value of users which is shown in the research process and lets the users involved. And it helps understand the thoughts of the users and create together, which promotes the designers to design standing in the users' position. Exhibition service design mainly provides the services to the visitors. And making a deep investigation on them is a necessary link before design. Exhibition space, as a kind of service of trans-information should emphasize the "user-centered" thinking mode and design method in the process of design. By combining the on the spot research method of contextual interview and field work with quantitative research of questionnaire to explore the real needs of users and understand the cognitive pattern and the behavior mode of the users can make the users feel happy and efficiency when they get the information. The Guggenheim Museum (Figure 1) which is designed by a famous American architect named Frank Lloyd Wright in 20th century is a landmark building of New York. His design has fully considered the need of special users (strollers or disabled people), and he designed the exhibition space with universality by the user-centered thinking mode.

\subsection{Systematization of Exhibition Service}

The so-called "system" is an aggregate made by a group of related elements interacting with one another for a specific goal. Any elements within the system will influence the effect of the target (Butler \& Tischler, 2015). The service design, as a kind of practice generally refers to the design of system and process, is committed to offer customers all-around services (Stickdorn \& Schneider, 2010).

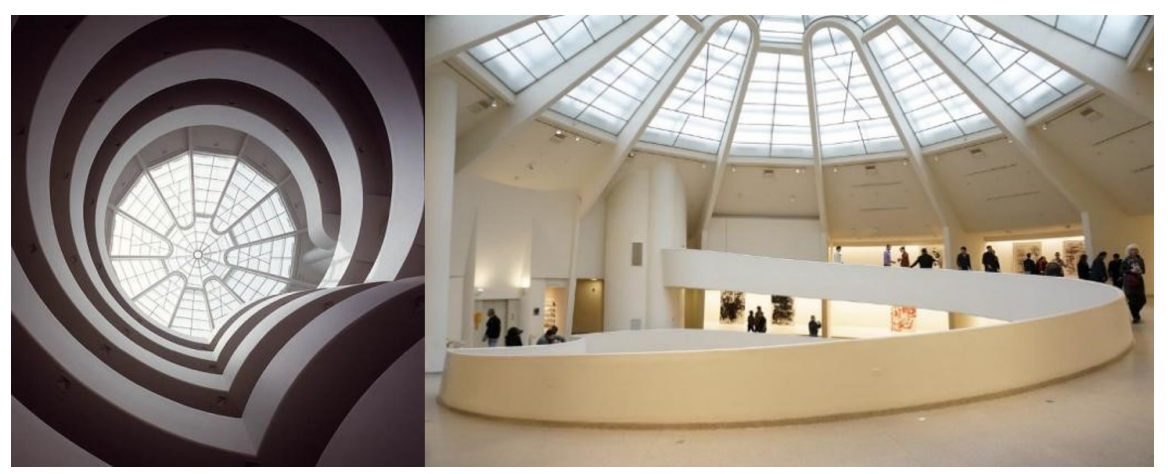

Figure 1. The Guggenheim museum. 
It makes the service design systemized and designs the contact point between users and products and environment to conduct systemized service ecology. Thus in the service system the harmony between the whole system and the each part should be kept, which makes the users experience a complete service process. Systematicness is also a kind of service feature made for the users in exhibition; it lays emphasis on the systematicness of the exhibition process and the design of the user-related contact point. It rectifies and intensifies the whole exhibition system and optimizes and process experience of users in the exhibition space. It sums up and sorts out the information by the travel graph of the users and the service layout making the service process be more perfect and systemized, and at the same time it is used in the exhibition space through the visual mode. The Swedish IKEA (Figure 2), its indoor exhibition space and guide can show the systematicness, and the visitors can visit the exhibition areas with different types through the established route of the guide system, thus it can help the users to develop complete systemized space cognition.

\subsection{The Combination of Functionality and Artistry}

The service design should take the users' field into consideration; both the physical need and the mental need should be understood sufficiently. The functionality is to satisfy the basic need in the process of realization, which is displayed through research of the basic need of the users; the mentality and feeling should be took into account, and design should display the artistry and sense of beauty to bring some unexpected pleasant surprised and additional emotional experience. Exhibition design is a design science with comprehensiveness, in the stage of creative design, it should pay attention to the users, exhibition content and space environment into consideration when carry out the research, that is to say it shouldn't be limited within the programme or the product placement of the single three-dimensional space and it should emphasize the combination of functionality and artistry. The exhibition space not only satisfies the visitors'

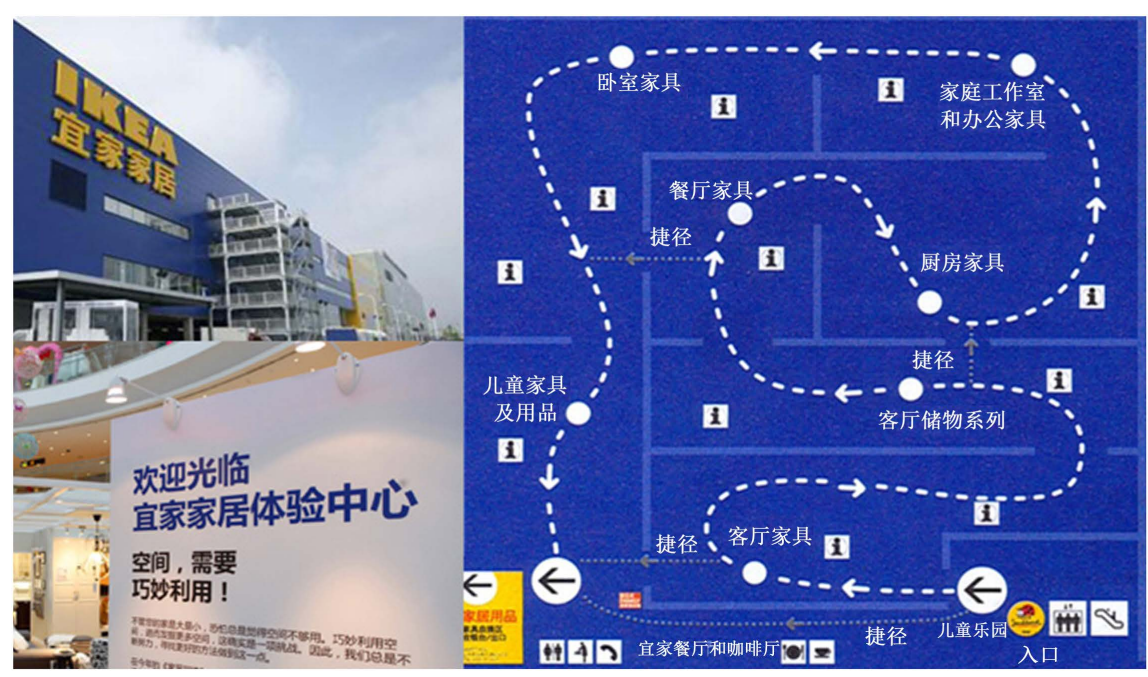

Figure 2. The circuit diagram of the IKEA. 
need of obtaining the knowledge, but also plans the basic size and space pattern according to the users' physical and mental needs to display the feature of the exhibition theme. Germany designer Buro Uebele designs a guide system with high identifiability for Stuttgart exhibition center of the trade fair (Figure 3), which is a masterwork with the combination of practicability and artistry.

\section{The Space Design Practice of the Aging Rehabilitation Aids Science Exhibition}

\subsection{Practical Background}

Pension industry development in our country is still in its beginning stage and the public for the cognition and understanding of aging rehabilitation is also relatively scarce, so the assistive technology couldn't be widely used in the lives of disabled people. Thus, a public space which provides the systemized knowledge of aging assistive technology for the public becomes a necessary link in the development of aging industry. The popular science experience hall of endowment rehabilitation assistive technology covering an area of about 200 square meters is constructed in Daxing District Beijing, as the first exhibition space of popular science experience in China, which aims at popularize aging assistive technology, hopes that visitors can not only obtain the knowledge about aging assistive technology but also get the intimate service and valuable experience. Taking the service design as the thinking guidance of exhibition space design provides a hall of endowment rehabilitation assistive technology with first-rate service and experience for visitors.

\subsection{The Plan of the Exhibition Design}

The exhibition will be focused on the review of history, rely on today and looking forward to the future, which will be the exhibits and the classification of the science popularization, it partly shows the development of the aging assistive technology, the product presentation in ancient time, the type of modernization aging assistive technology, the product presentation of the typical product and looking forward to future scientific products applied in the lives of old people. Based on the analysis of the relationship between the content and the proportion of the exhibition, the paper designs the layout of the exhibition space on the basis of the original building structure (Figure 4).

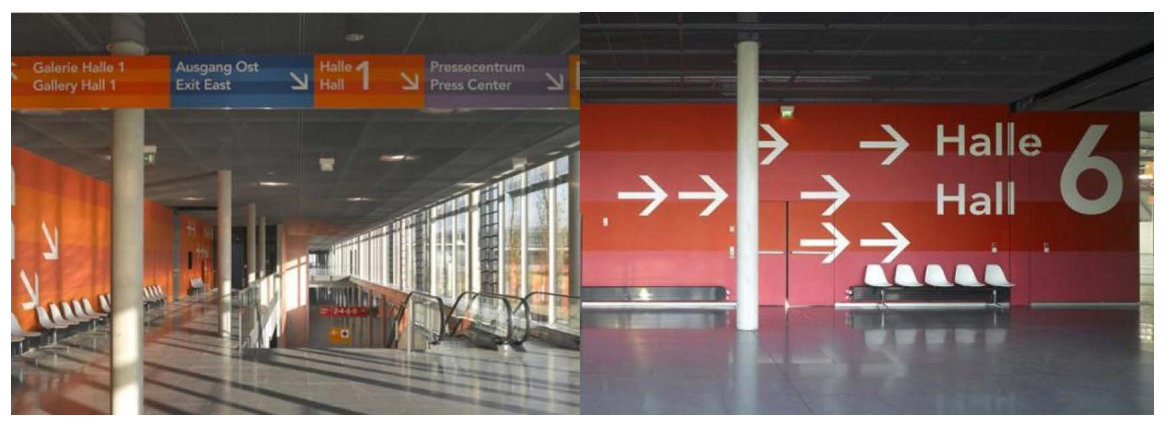

Figure 3. Stuttgart exhibition center. 


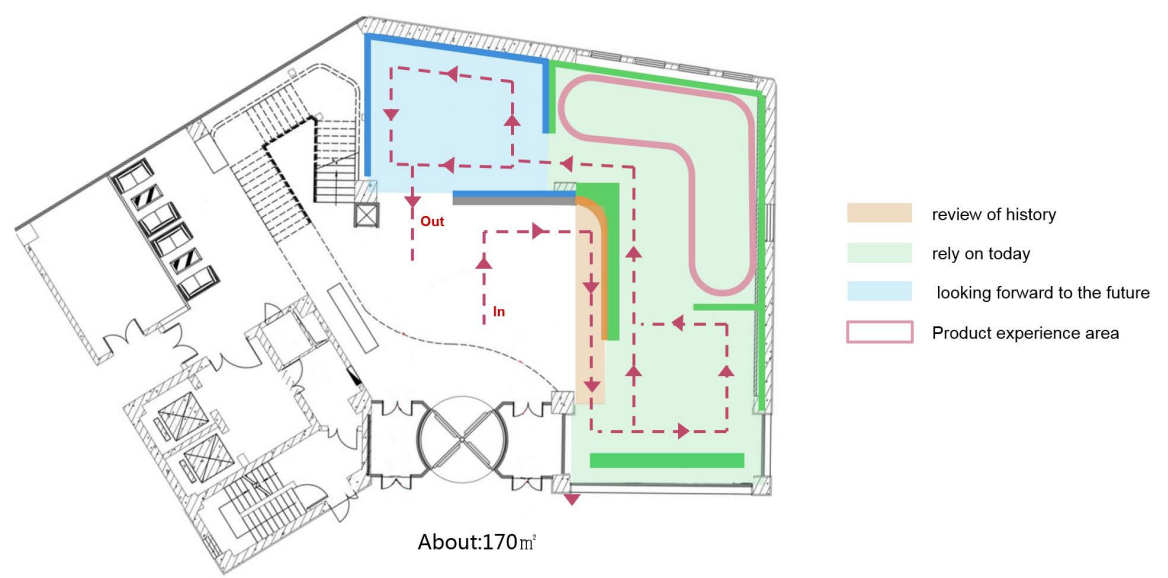

Figure 4. The layout of the exhibition space.

In order to design a complete visiting process, we map out a service blueprint for the exhibition space (Figure 5), used to display before, during and after stages and the whole related processes, to lay the theoretical basis for following exhibition design and the service direction.

\subsection{Service Factor Influencing Exhibition Space Design of Assistive Technology}

\subsubsection{Differentiation of Users' Needs}

Human society has stepped into high-tech information age, in the context of the development of social diversity, people's concept of consciousness presents a diversified state, and the differences between the needs of users is becoming more and more obvious. Individual age, experience, occupation, knowledge structure and other factors are the important factors contributing to individual value orientation, and different value orientation is the immediate cause of the different demands ( $\mathrm{Lu} \& \mathrm{Xie}, 2013$ ). In the process of service, diversity, ideas and cultural differences of users should be taken into consideration to real understand the users and create user value. The popular science experience hall belongs to the display space of social public service experience, the audience is more extensive, such as leaders at all levels, colleagues at home and abroad, research workers, medical practitioners, aging industry practitioners, young people, elderly disabled groups and media at all levels. The concept of consciousness and value orientation of visitors at different ages and engaging different occupations are not the same, leading to the different expected values or experience from the visiting of "the popular science experience hall of endowment rehabilitation assistive technology". Therefore, the survey of prophase users is particularly important, and the in-depth and comprehensive understanding of user research is needed. To understand the needs of different users for the exhibition space and expectation, it provides the individual and differentiated resolutions on the premise that the user's general requirements are satisfied.

\subsubsection{Explicit Display of Recessive Service Elements}

Service design, as an innovative concept to guide practice, has the characteristics 


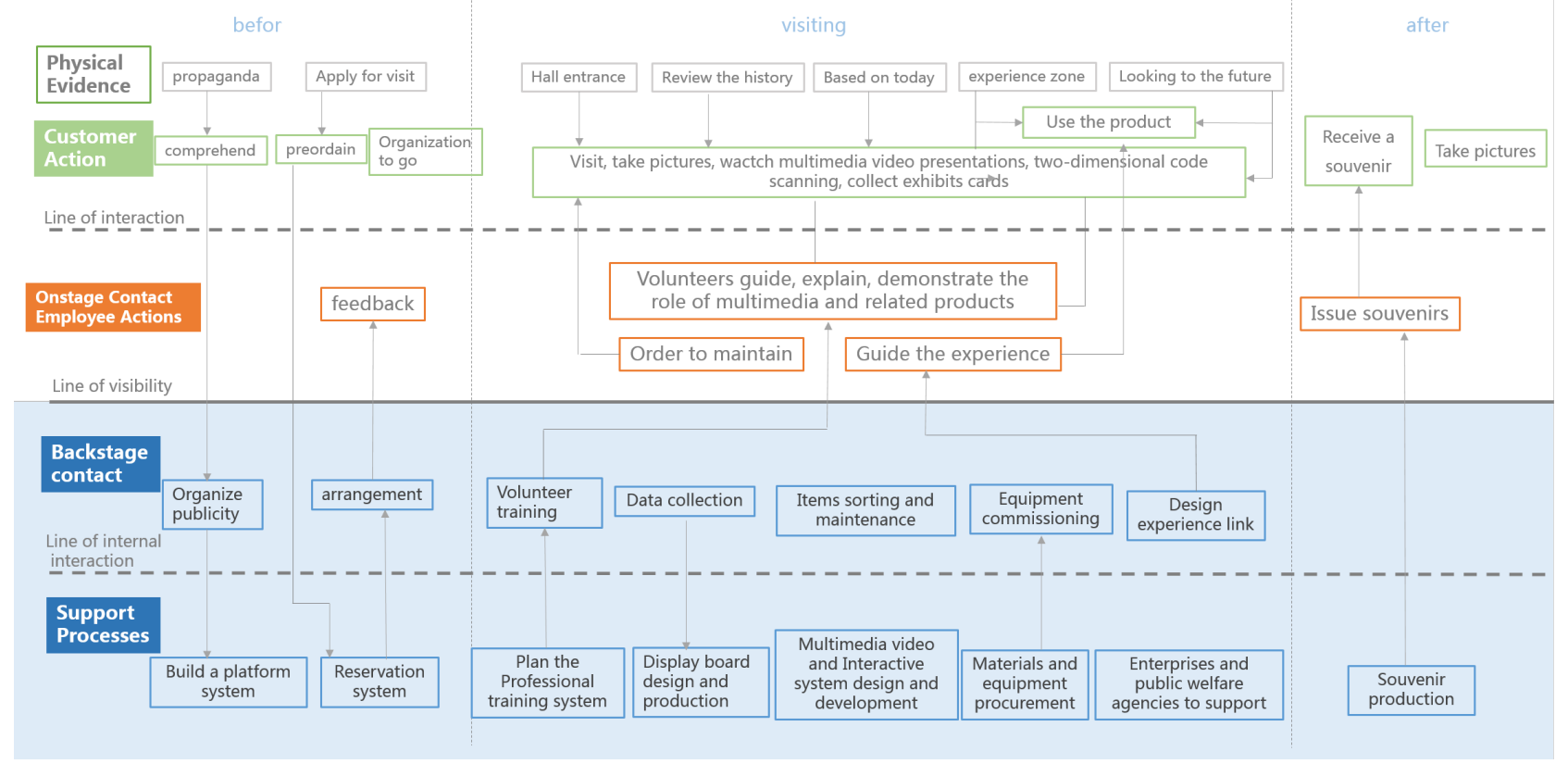

Figure 5. The service blueprint of exhibition hall.

of in corporeality, so it is necessary to use tangible product or environment as the carrier of service design. The explicit design of the service recessive elements is usually the researches on the user and the user's demand, transforming service content into task model and interaction model, which is provided for the users through some visual forms or some other patterns and it continuously improves the service content and form by user's evaluation (Zhou, Luo, \& Zhu, 2012). Used in the exhibition, not only the consideration of space, the tour route, exhibits on display is needed, but solution to the needs of potential users, the effective transmission of displayed information content, forming visual exhibition design, to show the imperceptible background service, fitting the user's psychological feeling or experience is necessary.

The science experience hall, as a public-served exhibition space has a certain particularity, the design based on needs of users, to extract the real inner needs of users and it's displayed through the creative design forms, which is convenient for users to experience more intimate service.

\subsection{The Design Results of Exhibition Space}

The total area of the popular science experience hall of endowment rehabilitation assistive technology is about 200 square meters, composed of three theme exhibitions and a product experience area (Figure 6). The exhibition area uses the open route as space browse form, and the contents of the exhibition use panes and multimedia equipment as the propagation medium of popular science of aging assistive technology. And the two-dimensional code scanning way can assist visitors to get more detailed understandings of the exhibition functions, the using scene and the using content.

Product experience area is the brightened dot of the entire exhibition space, 


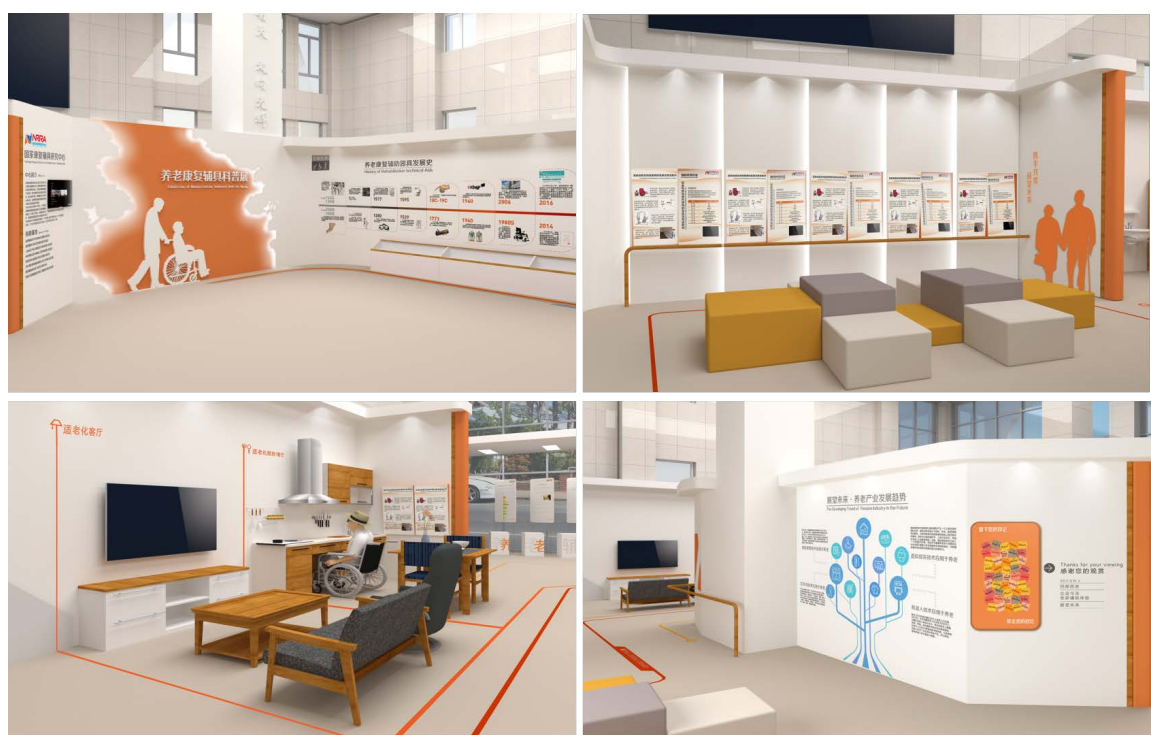

Figure 6. The popular science experience hall of endowment rehabilitation assistive technology.

and the experience area is divided into five elderly common home scenes: the living room, bedroom, dining room, bathroom and staircase, meanwhile the family living related auxiliary products are put in. Designers design a number of small game based experience projects, where the visitors by playing to the elderly, to complete the tasks of the game experience, experience the state after using assistive devices in the game. Experience is integrated into the display process, so that visitors can be keenly aware of the help brought to the lives of disabled elderly people, to achieve efficient communication, popularize knowledge of rehabilitation aids endowment.

\section{Service Oriented Exhibition Method Design}

Through the actual cases mentioned above, regarded the exhibition design as a service system, and the service is taken as the core concept to guide the display design. Finally, summed up the four point design method, hope it can be applied to the future display design.

\subsection{Improve the Display System to Control the Key Contact Point}

The whole exhibition space is a complex system composed of a number of factors, such as the content, form, space layout of the exhibition and so on. From the service point of view, the designer needs to extract the contact point of the user related services in the complex system, and each contact point will have different degrees of influence on the user's experience in the exhibition space. On this basis, it is necessary to find the most effective key points to research to improve the user experience. The key point of contact is the most important reference for the users' evaluation of the satisfaction in the whole exhibition system. The design effect of the key contact point can be tested by testing whether the user's satisfaction with the experience is higher than the user's previously 
expected level of satisfaction. The key point of contact is the highlight of the whole exhibition space design needed to be designed and managed with much more attention. The key contact point in the exhibition design is generally a series of interactive experience area protruding the exhibition purpose and the theme. This area needs to design valuable interactive experience for the user, to meet the users' full range and multi angle understanding of the exhibition purpose.

\subsection{Laying Emphasis on Environment-Create Immersion State}

The in-depth purpose of service design is to enhance the user's fine experience in the service process. Dr. M. Csikszentmihalyi proposed the "state of immersion" in 1975: People are put into an activity that is completely free from other distractions and this experience can make people happy (Csikszentmihalyi, 2012). People can pay at any cost for it and they do it entirely out of interest in them. Thus it can be seen that letting the visitors get into the state of immersion can make them obtain knowledge, improve the efficiency of understanding the display content, and the psychological level will be greatly satisfied. Therefore, in the exhibition design, creating an immersive display space for the audience can greatly meet the user's service recognition and satisfaction. To create a sense of immersion in the display environment, we first need to create an overall environment and space atmosphere fitting the exhibition theme. The design content should have explicit orientation, analyzing target users and the value meeting the needs of visitors. Provide valuable information to the viewer and explicit the value that the visitors can get by visiting the exhibition. Under joint excitation between the external space atmosphere and the internal design contents, the perceptual condition of the immersion experience can be built comprehensively, which can make visitors enter the state of empathy, that is to say getting into a state of immersion and have a more real psychological feelings and empathy.

\subsection{Enhanced Sensory Stimulation-Using Multimedia Technology}

In the process of planning the exhibition hall design, it should not be confined to the space planning and the display of the exhibition facilities, and the diversification of the manifestation mode of the exhibition content should also be reconsidered. The display design should pay attention to both the visitors' physiological sense, such as the visual, auditory, touch, smell, taste and the psychological activities such as emotion, thinking and so on. Therefore, by increasing the user's sensory stimulation can greatly improve the user experience effect and improve service satisfaction. The multimedia device can meet the interests of visitors from different age groups and different cultural levels and reduce the cursory browsing phenomenon, so that each one could find a suitable method of acquiring knowledge and has an in-depth understanding of the display contents. Multimedia technology is very popular in modern display design, not only the exhibition information can be conveyed to visitors through pictures, video, au- 
dio, 3D animation and other traditional multimedia facilities; modern VR, AR technology will combine the displayed contents and the computer network, making the exhibition content be richer and more novel. As the virtual reality technology in modern exhibition design, by human-computer interaction way visitors can perceive different situations activities, changing from passive to active, and actively participate in the process of the exhibition theme.

\subsection{Expand Value-Added Services-Making Unexpected Surprise}

In addition to meet the service value of the users in the display process, the appropriate expansion of value-added services for display design is also very important. The value added service can be used as fringe benefits for the users, which plays an important role in the whole service experience. The deep impression of exhibition design is often created in the process of experience, but as time goes by, this memory may gradually fade. Provide personalized emotional experience for the user in the service process, in addition to the process of visiting the exhibition, it should be extended to after-visit service, providing visitors with unexpected surprise, which can increase the user's favorable impression and leave a deep impression on the users.

\section{Conclusion}

Service design, as a widely used design concept in recent years, has its own special practical value. It integrates the service design into the exhibition design and excavates more meaningful values, using these value ideas to guide design practice. It takes the Beijing Rehabilitation Technical Aids for Aging Exhibition Hall as an example, integrates the ideas of service design into it, deeply explores the value of the user-centered experience exhibition space design and tries to extend the exhibition design to the service.

\section{Fund Project}

This article is the research result of Beijing Humanities and Social Sciences Fund Project "Construction of Public Education Rehabilitation Aids" (Item No.: Z16110000321612)

This article is the research result of Beijing Key Laboratory of network system and network culture.

\section{References}

Butler, D., Tischler, L., et al. (2015). Design to Grow: How Coca-Cola Learned to Combine Scale and Agility (and How You Can Too). New York: Simon \& Schuster.

Csikszentmihalyi, M. (2012). Beyond Boredom and Anxiety. Jossey-Bass.

Li, D., Ming, X. G., \& Kong, F. B. (2008). A Preliminary Study on Service Design. Machine Design and Research, 24, 6-10.

Karmarkar, U. (2004). Will You Survive the Services Revolution? Harvard Business Review, 82, 100-107.

Lu, M. J., \& Xie, J. (2013). Research on Design Method Based on User's Individual De- 
mand. Art and Design, NO. 4, 29-30.

Stickdorn, M., \& Schneider, J. (2010). This Is Service Design Thinking: Basics, Tools, Cases. Amsterdam: BIS Publishers.

Zhou, Y. X., Luo, S. J., \& Zhu, S. S. (2012). User Centered Service Design in Handheld Mobile Devices. Computer Integrated Manufacturing Systems, 18, 243-253.

Submit or recommend next manuscript to SCIRP and we will provide best service for you:

Accepting pre-submission inquiries through Email, Facebook, LinkedIn, Twitter, etc. A wide selection of journals (inclusive of 9 subjects, more than 200 journals)

Providing 24-hour high-quality service

User-friendly online submission system

Fair and swift peer-review system

Efficient typesetting and proofreading procedure

Display of the result of downloads and visits, as well as the number of cited articles Maximum dissemination of your research work

Submit your manuscript at: http://papersubmission.scirp.org/

Or contact adr@scirp.org 